\title{
Role of factors influencing on anaerobic process for production of bio hydrogen: Future fuel
}

\author{
R. Hema Krishna \\ Department of Chemistry, University of Toronto, Ontario, Canada. M5S $3 H 6$ \\ *Corresponding authorE-mail: hkravuri32@gmail.com
}

\begin{abstract}
The process of anaerobic treatment is indeed more complex than the aerobic systems, and for this reason, the operation of an anaerobic treatment system should have a solid understanding of the important factors like temperature, $\mathrm{pH}$, bicarbonate alkalinity, VFA, inorganic salts, sulfide soluble salts, in operation, heavy metals and nutrient requirement, in operation and control and are associated with the stability of the biological process involved. Thus the review was directed especially to these.
\end{abstract}

Keywords: Anaerobic process, bio hydrogen, environmental factors, heavy metals, nutrients.

\section{Introduction}

Anaerobic digestion is a good biological process and has a long history and a worldwide application in treating sewage sludge, this biotechnology is still far from being optimized. The organic material in sewage sludge is in the form of particulates, and this makes hydrolysis of these particulates the obstacle of the whole anaerobic digestion [1-3]. Anaerobic digestion is the natural process in which complex organic materials are broken down into simpler compounds in the absence of oxygen by the action of several micro-organism communities. Anaerobic digestion consists of four biochemical steps: hydrolysis - hydrolytic bacteria remove polymers to monomers; acidogenesis acidogenic bacteria remove monomers to short carboxylic acid, $\mathrm{CO}_{2}$, hydrogen and alcohol; acetogenesis - the products of the previous phase are removed to acetic acid; methanogenesis - methane is built of the acetic acid [4-7]. The most important environmental benefit of the anaerobic digestion process is the production of biogas, a renewable energy source, which can be used as fuel for the internal combustion engines, for direct heating and, under better efficiency, in cogeneration, for electricity production as well [8]. The production of biogas based on biomass generates the reduction of fossil fuel use and enables the lowering of $\mathrm{CO}_{2}$ levels with fossil $\mathrm{C}$ origin, in accordance with EU directives regarding the climate changes and supporting the reduction of the greenhouse gases emission especially, not mentioning the use of a local energy resource. Apart from yield of biogas, anaerobic digestion creates solid and liquid by-products, which can have value as a fertilizer or soil amendment. The biogas produced by anaerobic digestion is a blend consisting mainly of methane $\left(\mathrm{CH}_{4} \approx 60 \%\right.$ by volume), carbon dioxide $\left(\mathrm{CO}_{2} \approx 40 \%\right.$ by volume), and small traces of hydrogen sulphide $\left(\mathrm{H}_{2} \mathrm{~S}\right)$, hydrogen $\left(\mathrm{H}_{2}\right)$, nitrogen $\left(\mathrm{N}_{2}\right)$, carbon monoxide $(\mathrm{CO})$, oxygen $\left(\mathrm{O}_{2}\right)$, water vapor $\left(\mathrm{H}_{2} \mathrm{O}\right)$ or other gases and vapors of various organic compounds. Due to the complexity of the bioconversion processes, many factors affecting the performances of an anaerobic digester were analyzed and depicted [9-10]. These can be divided in three main classes: (i) feedstock characteristics, (ii) reactor design and (iii) operational conditions. In the present paper, Among the operational conditions, Temperature, $\mathrm{pH}$, Bicarbonate Alkalinity, VFA, Inorganic Salts, Sulfide Soluble Salts, in operation, Heavy Metals and Nutrient Requirement are the most important parameters, thus the research was directed especially to these

\section{Results and discussion}

\subsection{Factors influencing the Anaerobic Process}


Process instability is usually indicated by a rapid increase in the concentration of volatile acids in the 1 st stage of the reaction; low $\mathrm{pH}$ with concurrent reduction in methane gas production, indicated that the methane bacteria are more susceptible to upset. Acclimatization of the microorganisms to a substrate was reported to take more than five weeks. Sufficiently acclimated bacteria have shown greater stability towards stress-inducing events such as hydraulic overloads, fluctuations in temperature, fluctuations in volatile acid and ammonia concentrations etc. Several environmental factors effect anaerobic digestion, by altering the parameters such as specific growth rate, decay rate, gas production, substrate utilization, start-up and response to changes in the input. Table 1. Depicts the factors, which normally have significant control over anaerobic process effectively

Table 1: Factors affecting anaerobic process operation [11-12]

\begin{tabular}{ccc} 
& Table 1: Factors affecting anaerobic process operation [11-12] & \\
\hline Factor & Range & Normally Used \\
Temperature & Mesophilic $\left(29\right.$ to $\left.38^{0} \mathrm{C}\right)$ & 7.0 \\
$\mathrm{pH}$ & Thermophilic $\left(49\right.$ to $\left.57^{\circ} \mathrm{C}\right)$ & To buffer the capacity for handling the VFA \\
Bicarbonate Alkalinity & 2500 to $5000 \mathrm{mg} / \mathrm{L}$ & Stimulation \\
VFA & 20 to $200 \mathrm{mg} / \mathrm{L}$ & Toxic \\
Inorganic Salts & Low concentration & Non Toxic \\
High Concentration & Toxic \\
Sulfide Soluble Salts & 200mg/L & Depending upon COD load \\
Heavy Metals & Low concentration & N and P source required
\end{tabular}

\subsection{Retention time}

The hydraulic retention time (HRT), which depends on wastewater characteristics and environmental conditions must be long enough to allow metabolism by anaerobic bacteria in digesters. Digesters based on attached growth have a lower HRT (1-10 days). The retention times of mesophilic and thermophilic digesters range between 25 and 35 days but can be lower.

\section{$2.3 \mathrm{pH}$}

Most methanogenic bacteria functions in a $\mathrm{pH}$ range between 6.7 and 7.4, but optimally at $\mathrm{pH} 7.0-7.2$, and the process may fail if the $\mathrm{pH}$ is close to 6.0. Acidogenic bacteria produce organic acids, which tend to lower the $\mathrm{pH}$ of the bioreactor. Under normal conditions, this $\mathrm{pH}$ reduction is buffered by the bicarbonate that is produced by methanogens. Under adverse environmental conditions, the buffering capacity of the system can be upset, eventually stopping the production of methane. Acidity is inhibitory to methanogens than of acidogenic bacteria. An increase in volatile acid levels thus serves as an early indicator of system upset. Monitoring the ratio of total volatile acids (as acetic acid) to total alkalinity (as calcium carbonate) has been suggested to ensure that it remains below 0.1 .

\subsection{Temperature}

As in all biological processes, anaerobic processes are also affected by temperature. Generally speaking, the higher the temperature, the higher is the microbial activity until an optimum temperature is reached. A further increase of the temperature beyond its optimum value results in a precipitous decrease in activity. Anaerobic process comprising sludge digestion and gas production can take place over a wide range of temperatures $\left(4-600^{\circ} \mathrm{C}\right)$. Once, an effective temperature range is established, small fluctuations can result in a process upset. Although, most of the sludge digesters are operated in the mesophilic ranges $\left(30-400^{\circ} \mathrm{C}\right)$, Methanogeniss is known to occur at temperatures as low as $40^{\circ} \mathrm{C}$. The effect of increasing temperature in the $4-250^{\circ} \mathrm{C}$ ranges is profound. The rate of gas production has been reported to change from 100 to $400 \%$ for a 12 -degree increase in temperature. At temperatures of $40-450^{\circ} \mathrm{C}$, the microbial activity is significant, but due to the high decay rate, the yield coefficient of methane bacteria approaches zero, and thus renders continuous operation difficult at that temperature. Thermophilic processes have a constant methane production rate, independent of temperature in the range of $50-700{ }^{\circ} \mathrm{C}$. The rate is dependent upon the substrate and about $25-50 \%$ higher than the mesophilic rate at $350^{\circ} \mathrm{C}$.

In psychrophilic conditions, mesophilic or thermophilic ranges, uniformity of temperature over the entire vessel contents is of paramount importance to anaerobic digestion. Rapid alterations in the reactor temperature of even a few degrees can result in a marked upset in microbial metabolism and may necessitate several days for the recovery. Adequate mixing of reactor contents by paddle can provide a consistent temperature throughout the system. Since the majority of industries generate greater quantities of waste heat as a component of their effluent streams, the maintenance of anaerobic digester temperature below $250^{\circ} \mathrm{C}$ presents little difficulty and mesophilic systems can be 
designed to take advantage of the waste energy. Methane production has been documented under a wide range of temperatures. In municipal wastewater treatment plants, anaerobic digestion is carried out in the mesophilic range at temperatures from $25^{\circ} \mathrm{C}\left[77^{\circ} \mathrm{F}\right]$ to $40^{\circ} \mathrm{C}\left[104^{\circ} \mathrm{F}\right]$ with the optimum at approximately $35^{\circ} \mathrm{C}\left[95^{\circ} \mathrm{F}\right]$. Thermophilic digestion operates at temperature ranges of $50-65^{\circ} \mathrm{C}\left[122^{\circ} \mathrm{F}-149^{\circ} \mathrm{F}\right]$. It allows higher loading rates and is also conductive to greater destruction of pathogens. One drawback is its higher sensitivity to toxicants. Because of their slower growth as compared with acidogenic bacteria, methanogenic bacteria are very sensitive to small changes in temperature, which leads to a decrease of the maximum specific growth rate while the half-saturation constant increases. Thus, a mesophilic digester must be designed to operate at temperatures between $30^{\circ} \mathrm{C}\left[86^{\circ} \mathrm{F}\right]$ and $35^{\circ} \mathrm{C}$ $\left[95^{\circ} \mathrm{F}\right]$ for their optimal functioning.

\subsection{Nutrients}

Anaerobic wastewater treatment processes are often used for industrial wastes with only minor amounts of nutrients present. This might result in nutrient deficiency, unless additional nutrients are added. Investigations by [13] have shown that the nitrogen and phosphorus content of the volatile suspended solids produced during anaerobic digestion is approximately $10.5 \%$ and $1.5 \%$ respectively. Often the COD/N ratio or the COD/P ratio is used to describe the nutrient requirements. Only the nitrogen requirement is considered, as the phosphorus requirement is of a magnitude that has only minor economic implications. Optimum N/P ratio is considered to be 350/7. A value around 400/7 must be regarded reasonable for high rate anaerobic processes $(0.8-1.2 \mathrm{~kg}$ COD/ kg VSS. day). For low rate processes $(<0.5 \mathrm{~kg}$ $\mathrm{COD} / \mathrm{kg}$ VSS. day), the COD/N ratio was observed to increase dramatically to values of 100/7 or more. Nutrients other than nitrogen and phosphorus are essential for anaerobic process. Table. 2 depicts the various nutrients and their ideal concentration and desired excess concentrations for a reasonably proper anaerobic treatment process. The importance of nickel for methanogens has been realized only recently. The presence of trace metals such as molybdenum, selenium, tungsten and nickel is probably necessary for the activity of several enzyme systems. The addition of nickel, cobalt and molybdenum increased total gas (including methane) production by $42 \%$ and allowed greater volumes of waste to be effectively treated by decreasing the reactor residence time. These effects were considered to be result of accumulation of a thicker methanogenic fixed film. The addition of nickel to a culture of methanogens was reported to increase the level of acetate utilization and Methanosarcina spp. concentration. Nitrate reduction and COD utilization increased significantly when molybdenum and selenium were added to an anaerobic system.

Table 2: Nutrient Requirement for Anaerobic treatment [14]

\begin{tabular}{|c|c|c|c|}
\hline Elements & $\begin{array}{c}\text { Requirement (mg/g } \\
\text { COD) }\end{array}$ & $\begin{array}{c}\text { Desired excess } \\
\text { concentration }(\mathrm{mg} / \mathrm{L})\end{array}$ & Typical form of addition \\
\hline \multicolumn{4}{|c|}{ Macronutrients } \\
\hline Nitrogen & $5-15$ & 50 & $\mathrm{NH}_{3}, \mathrm{NH}_{4} \mathrm{Cl}, \mathrm{NH}_{4} \mathrm{HCO}_{3}$ \\
\hline Phosphorus & $0.8-2.5$ & 10 & $\mathrm{NaH}_{2} \mathrm{PO}_{4}$ \\
\hline Sulfur & $1-3$ & 5 & $\mathrm{MgSO}_{4} \cdot 7 \mathrm{H}_{2} \mathrm{O}$ \\
\hline \multicolumn{4}{|c|}{ Micronutrients } \\
\hline Iron & 0.03 & 10 & $\mathrm{FeCl}_{2} \cdot 4 \mathrm{H}_{2} \mathrm{O}$ \\
\hline Cobalt & 0.003 & 0.02 & $\mathrm{CoCl}_{2} \cdot 2 \mathrm{H}_{2} \mathrm{O}$ \\
\hline Nickel & 0.004 & 0.02 & $\mathrm{NiCl}_{2} \cdot 6 \mathrm{H}_{2} \mathrm{O}$ \\
\hline Zinc & 0.02 & 0.02 & $\mathrm{ZnCl}_{2}$ \\
\hline Copper & 0.004 & 0.02 & $\mathrm{CuCl}_{2} \cdot 2 \mathrm{H}_{2} \mathrm{O}$ \\
\hline Manganese & 0.004 & 0.02 & $\mathrm{MnCl}_{2} \cdot 4 \mathrm{H}_{2} \mathrm{O}$ \\
\hline Molybdenum & 0.004 & 0.05 & $\mathrm{NaMoO}_{4} \cdot 2 \mathrm{H}_{2} \mathrm{O}$ \\
\hline Selenium & 0.004 & 0.08 & $\mathrm{Na}_{2} \mathrm{SeO}_{3}$ \\
\hline Tungsten & 0.004 & 0.02 & $\mathrm{NaWO}_{4} \cdot 2 \mathrm{H}_{2} \mathrm{O}$ \\
\hline Boron & 0.004 & 0.02 & $\mathrm{H}_{3} \mathrm{BO}_{3}$ \\
\hline \multicolumn{4}{|c|}{ Common cations } \\
\hline Sodium & & $100-200$ & $\mathrm{NaCl}, \mathrm{NaHCO}_{3}$ \\
\hline Potassium & & $200-400$ & $\mathrm{KCl}$ \\
\hline Calcium & & $100-200$ & $\mathrm{CaCl}_{2} \cdot 2 \mathrm{H}_{2} \mathrm{O}$ \\
\hline Magnesium & & $75-250$ & $\mathrm{MgCl}_{2}$ \\
\hline
\end{tabular}

\subsection{Environmental factors}

Anaerobic processes are sensitive to $\mathrm{pH}$ and inhibitory substances. A pH value near neutral is preferred and below 6.8, the methanogenic activity is inhibited. Because of high $\mathrm{CO}_{2}$ content in gases developed in anaerobic processes (30-35\% 
$\mathrm{CO}_{2}$ ), a high alkalinity is needed to assure $\mathrm{pH}$ near neutrality (3000-5000 mg/L required). For sludge digestion, sufficient alkalinity is produced by breakdown of protein and amino acids to produce ammonia, which combines with $\mathrm{CO}_{2}$ and $\mathrm{H}_{2} \mathrm{O}$ to form alkalinity as $\mathrm{NH}_{4}\left(\mathrm{HCO}_{3}\right)$. For industrial wastewater applications, especially for waste containing mainly carbohydrates, it is necessary to add alkalinity for $\mathrm{pH}$ control. Substances inhibitory to anaerobic processes (e.g. $\mathrm{NH}_{3}, \mathrm{H}_{2} \mathrm{~S}$, and various other organic and inorganic compounds) are considered [15].

\subsection{Flow and loading variations}

Wide variations in influent flow and organic loads can upset balance between acid fermentation and methanogenesis in anaerobic processes. For soluble, easily degradable substrates, such as sugars and soluble starches, acidogenic reactions can be much faster at high loadings and may increase the reactor VFA and hydrogen concentrations and depress the $\mathrm{pH}$. Higher hydrogen concentrations can inhibit propionic and butyric acid conversion. The lower $\mathrm{pH}$ can inhibit methanogenesis. Flow equalization or additional capacity must be provided to meet peak flow and loading conditions [16].

\subsection{Inhibitory substances}

Inhibition of the anaerobic digestion process is mediated to varying degrees by toxic materials present in the system. These substances may be components of the influent wastewater or byproducts of the metabolic activities in the digester. For two reasons, toxicity is, perhaps, a larger problem with anaerobic treatment than the aerobic treatment. First, the concentrations of organic material treated are often so much higher, and with higher concentration of wastewater organic matter, the concentration of other materials, including those that are inhibitory, are likely to be higher as well. Second, the specific growth rates of the anaerobic microorganisms are much lower. Low specific growth rates mean that the biological safety factor that is economically acceptable is lower, thereby putting the anaerobic process at greater risk in general [14]. Inhibition may also arise as the consequence of increased levels of ammonia alkali and the alkaline earth metals, and the heavy metals in the system. The latter are considered as the most common and the major factors governing reactor failure. The inhibition and toxicity models used for anaerobic systems can be divided into three categories: empirical, monod-type with adjustable bio kinetic constants, and the inhibition coefficient models.An empirical model for describing the recovery pattern from slug addition of toxicants in methanogenic, acetate-fed systems has been developed by [17]. This model was successfully used to describe the recovery pattern for a wide variety of toxicants such as cyanide, chloroform, formaldehyde and copper. The recovery pattern model adequately predicts the period of zero gas production. The threshold and lethal doses can also be estimated.

\subsubsection{Controlling toxicity in general}

From a control standpoint, inhibitory substances need to be reduced in concentration in some manner to below a toxic threshold. Elimination of toxic material from the waste stream and the dilution of the waste stream (e.g. with another waste stream) are approaches that might be used in any situation. Dilution may be quite expensive, as it could result in a larger reactor to achieve a given treatment efficiency. Other methods to control toxicity are specific to the given toxicant [18]. Toxicity normally comes from a soluble material, one that is available to the microorganisms. Toxicity of heavy metals, such as copper or zinc, can be removed by addition of sulfide, which forms an insoluble precipitate with those metals. This can be done by addition of sulfates to the system. However, the addition rate must be carefully controlled, because too many sulfates reduces methane formation and can lead to excessive formation of sulfides which are themselves inhibitory. Toxicity from sulfides can be reduced by gas stripping from the reactor. A higher gas production and lower $\mathrm{pH}$ can be beneficial in reducing toxicity concentration below an inhibitory level. Maintaining a lower $\mathrm{pH}$ can reduce ammonia toxicity by shifting acid-base equilibrium towards its conjugate acid pair, $\mathrm{NH}^{+}$. [16] Precipitation, Complex formation and Stripping occur during treatment of many wastes, good examples being primary and secondary sludges from municipal wastes, which contain very high concentrations of synthetic detergents, fatty acids, and heavy metals. However, some industrial wastewaters do not have the same breadth of materials able to complex or precipitate toxic materials. The potential toxicity of materials in wastewaters to anaerobic treatment can be determined best through laboratory bioassay procedures, such as anaerobic toxicity assay [21].

\subsubsection{VFA inhibition}

Anaerobic reactor instability is generally manifested by a marked and rapid increase in volatile fatty acids concentrations. This is frequently indicative of the failure of the methanogenic population due to other environmental disruptions such as shock loading, nutrient depletion or infiltration of inhibitory substances. Acetate has been described as the least toxic of the volatile acids, while propionate has often been implicated as a major effect of digester failure. Microbial growth was observed to be significantly inhibited at $35 \mathrm{~g} / \mathrm{L}$ acetate in one investigation. Sudden increase in the concentration of either acetic or n-butyric acid has reportedly caused stimulation rather than inhibition of methanogens. 


\subsubsection{Ammonia-nitrogen inhibition}

Ammonia, which is a base, combines with carbon dioxide and water to form ammonium bicarbonate, the bicarbonate being a natural buffer. Ambiguities exist in regard to the degree of toxicity ascribed to ammonia. Using pilot plant experimental data and documentary evidence, the following facts were observed: 1. Operational Stability was not detrimentally affected by ammonia and nitrogen concentrations in excess of threshold levels. 2. System accommodation of very high concentrations of free ammonia was not accounted.3. Balanced digester conditions were enhanced to a marked degree of initial acclimation procedures. In a reactor system that has not been previously acclimated to high ammonia loadings, shock loadings of high ammonia concentration generally caused rapid production of VFAs such that the buffering capacity of the system may not be able to compensate for the decrease in $\mathrm{pH}$. Further depression of alkalinity and reduction of $\mathrm{pH}$ may result in reactor failure. In a reactor under steady-state conditions and acclimated to high ammonia loading, relatively high concentrations of VFAs will be counteracted by the ammonium bicarbonate buffering capacity of the system. In anaerobic digester operations, ammonia is frequently assessed as ammonianitrogen. The ammonia nitrogen concentration. Thus, although ammonia is inhibitory to the methanogenic phase of digestion, the effects are reversible and may be avoided to a certain extent by digester acclimation.

\subsubsection{Effects of sulfates and sulfides}

The sulfates and other oxidized compounds of sulfur are easily reduced to sulfide under the conditions prevalent in anaerobic digesters. Sulfur-containing amino acids of protein can also undergo degradation to sulfides. These compounds are of significance when anaerobic treatment is considered for industrial processes, which tends to produce large quantities of sulfides in their waste stream. The sulfides formed by activity of the reactor microorganisms may be soluble or insoluble, depending upon their associated cations. When the salts are insoluble, they have negligible effects of digestion. Iron addition, for example, can suppress sulfide inhibition. Sulfides require special attention in case of all anaerobic processes as they can lead to a lot of corrosion and other problems. Sulfides may come from industrial sources or be formed in the anaerobic units as a result of the reduction of sulfates present in the wastewaters. High sulfates may come from the original water supplies of the city or industrial wastes. They may also come from infiltration of brackish ground waters where sewers pass through such areas. The extent to which sulfates $\left(\mathrm{SO}_{4}{ }^{2-}\right)$ contained in the influent to the UASB are converted to sulfides $\left(\mathrm{S}^{2-}\right)$ depends on various factors and removals can vary from 50 to $90 \%$ or more. The sulfates so removed are converted to sulfides:

$$
\mathrm{SO}_{4}{ }^{2-} \longrightarrow \mathrm{S}^{2-}
$$

Sulfides formed equal 1/3rd of the sulfates removed. Sulfides $\left(\mathrm{S}^{2-}\right)$ can be toxic above $100 \mathrm{mg} / \mathrm{L}$., but are partly converted to $\mathrm{H}_{2} \mathrm{~S}$, which is less toxic. Depending on the $\mathrm{pH}$ and dissociation constant at given temperature, the unionized $\mathrm{H} 2 \mathrm{~S}$ can be determined.

$$
\mathrm{H}_{2} \mathrm{~S} \longrightarrow 2 \mathrm{H}++\mathrm{S}^{2-}
$$

The free or unionized $\mathrm{H} 2 \mathrm{~S}$ fraction at $\mathrm{pH}$ 7.0. To 7.4 may be about $0.2-4.0$ of the sulfides present and can be toxic to the process at about $250 \mathrm{mg} / \mathrm{L}$ for granular sludge (for dispersed sludge the limit is $50 \mathrm{mg} / \mathrm{L}$ ). About $50 \%$ or more can then diminish gas production and the corresponding economy of the system also diminished. Sulphate reduction also consumes some COD and to that extent, less COD is available for gas production. Sulfides tend to remain dissolved in the liquid phase if COD/SO4 ratio is less than 7-10, though ratios as low as 0.5 have been operated with, as long as $\mathrm{H}_{2} \mathrm{~S}$ is less than $200 \mathrm{mg} / \mathrm{L}$. When the $\mathrm{COD} / \mathrm{SO}_{4}{ }^{2-}$ ratio is higher than 10 , sulfide tends to get tripped from the liquid phase to the gas phase owing to the higher rate of gas production. The dissolved $\mathrm{S}^{2-}$ still remaining in the liquid phase goes out in the effluent. At pH 7.2, the residual sulfides may be about $25 \%$ of the sulfides formed earlier, and will have an immediate oxygen demand at the rate of $2 \mathrm{~g}$ of $\mathrm{O} 2$ per $1 \mathrm{~g}$ of sulfides:

$$
\mathrm{S}^{2-}+2 \mathrm{O}_{2} \longrightarrow \mathrm{SO}_{4}{ }^{2-}
$$

This immediate oxygen demand has to be met by aerating the effluent as stated. This again reduces, to some extent, the economy of the UASB system. Discharge standards in India generally allow sulfides up to $2 \mathrm{mg} / \mathrm{L}$ to be discharged to surface waters and $5 \mathrm{mg} / \mathrm{L}$ to marine coastal waters.

Possibilities of conversion of sulfides into elemental sulfur from anaerobic effluents high in sulfides have been successfully developed and provide interesting opportunities for by-product recovery of sulfur where sulfates/sulfides are in high enough concentration in raw wastewater. This approach appears more favorable to follow than aerating the effluent. It could also be used to treat exhaust gases.

In treating wastes containing $\mathrm{SO}_{4}{ }^{2-}, \mathrm{SO}_{3}{ }^{2-}$ etc. the following biochemical reaction takes place.

$$
8 \mathrm{H}+\mathrm{SO}_{4}{ }^{2-} \longrightarrow \mathrm{H}_{2} \mathrm{~S}+2 \mathrm{H}_{2} \mathrm{O}+2 \mathrm{OH}^{-}
$$


The reduction of $\mathrm{SO}_{4}{ }^{2-}$ is accomplished by strict anaerobic organisms. These organisms are only able to use a limited number of electron donors, e.g. particularly hydrogen. The occurrence of sulphate reduction is important for the following three aspects: 1 . The methane yield per unit weight of COD removed will decrease: A complete reduction of $\mathrm{SO} 42$ - theoretically can occur at $\mathrm{COD} / \mathrm{SO}_{4}{ }^{2-}$ ratios exceeding 0.67 . However, as sulphate reducers can only use a limited number of substrates, in practice significantly higher $\mathrm{COD} / \mathrm{SO}_{4}{ }^{2-}$ ratios are required to accomplish a complete sulphate reduction. The reduction of $1.5 \mathrm{~g}$ of $\mathrm{SO}_{4}{ }^{2-}$ is equivalent at $1.0 \mathrm{~g}$ of $\mathrm{COD}$ (viz. per $\mathrm{Kg} \mathrm{SO}_{4}{ }^{2-}$ reduced $0.233 \mathrm{~m} 3$ less methane will be produced at STP). 2. The reduction of sulphate will result in the formation of $\mathrm{H}_{2} \mathrm{~S}$, which is toxic for methanogens. However in practice a severe inhibition of methanogens as a rule only occurs at $\mathrm{COD} / \mathrm{SO}_{4}{ }^{2-}$ ratios below 7-10.An appreciable part of the $\mathrm{H} 2 \mathrm{~S}$ formed will be stripped off from the liquid phase as a result of the relatively higher gas production at higher $\mathrm{COD} / \mathrm{SO}_{4}{ }^{2-}$ ratios.In the neutral $\mathrm{pH}$ range approximately $50 \%$ of the dissolved sulfide is present in the undissociated (volatile) form $\left(\mathrm{H}_{2}\right) 3$. The formation of sulfide may cause considerable malodor nuisance to the environment. It is clear from the above, sulphate reduction may be detrimental to the anaerobic treatment process itself, with respect to the development of a balanced acetogenic methanogenic population. Instead of methanogens using the hydrogen, predominantly sulphate reducers will grow. Such a situation along with availability of sulphate and improper hydrogen utilization may result in severe accumulation of propionic acid and other acetogenic substrates.

\subsubsection{Role of inter-species transfer of hydrogen and formate}

Because of unfavorable thermodynamics, oxidation of propionate and butyrate is only possible if $\mathrm{H}_{2}$ is to move efficiently, i.e., a very low hydrogen partial procedure is necessary. Propionate degradation is only possible below a partial pressure of 10-4 atm $\mathrm{H}_{2}$. In granules degrading a mixture of acetate, propionate and butyrate, a clear correlation exists between the degradation rate of propionate or butyrate and the hydrogen partial pressure. A slight increase in the partial pressure of hydrogen results immediately in a decrease in the degradation rate of the two volatile fatty acids. In anaerobic systems, low hydrogen partial pressure can only be achieved by interspecies transfer of molecular hydrogen from hydrogen-producing bacteria i.e. Hydrogen-oxidizing methanogens. In granular sludge microclines consisting of syntrophic, propionate or butyrate degrades and hydrogen-utilizing methanogens have been observed. The degradation of e.g. propionate and butyrate could take place in these microclines. Disintegration of volatile fatty acid degrades granules, and hereby also disintegration of the microorganisms, led to a decrease in the degradation rate of propionate and butyrate, indication the importance of microclines. Besides the observed microclines in granules where the degradation of propionate or butyrate could happen, thermodynamic considerations have shown that the most effective degradation of propionate and butyrate will take place in these microclines where the distance between the syntrophic bacteria is small. Besides hydrogen transfer, formate transfer also has been proposed to play significant role in the syntrophic oxidation of fatty acids in flocs or dispersed cultures where the distance between the bacteria is high (more than $10 \mathrm{~mm}$ ). However, recent experiments showed that interspecies formate transfer is of no importance during degradation of propionate and butyrate in granules, perhaps due to the small distance between the bacteria. Electron transfer in the granules occurred only through interspecies hydrogen transfer.

\subsubsection{Heavy metals inhibition}

The most common agents of inhibition and the failure of sewage sludge digesters are reported to be contaminating heavy metals. Heavy metals in the soluble state are in general regarded to be more significant in reactor toxicity than the insoluble forms. According to [20], failure of the digester system may result when the free concentration of heavy metals rises beyond a particular threshold concentration. This threshold concentration appears to be directly related to the sulfide ion concentration of the digesting sludge. Anaerobic digestion also reduces the valence states of some heavy metals. Copper may be reduced from the trivalent to the divalent state. This reduces the quantity of the precipitating agent, such as sulfide, necessary for the removal of the metal ion from the solution. The heavy metals can be removed from anaerobic systems by adsorption. [17] Reported that, recovery of an anaerobic filter from the effects of nickel toxicity largely depended upon the concentrations in relation to the exposure time of the system. At exposure times of less than one day, nickel concentrations of upto $800 \mathrm{mg} / \mathrm{L}$ were observed to result in little decrease in gas production. However, gas production was halted when $2400 \mathrm{mg} / \mathrm{L}$ nickel was added to the system for a period of one hour. Copper was demonstrated to inhibit the digestion process when present as its sulphate salt at concentrations of $200-230 \mathrm{mg} / \mathrm{L}$. However, when present as copper hydroxide, with $520 \mathrm{mg} / \mathrm{L}$ as copper, the effects were reported to be negligible. At concentrations of copper below $200 \mathrm{mg} / \mathrm{L}$, the lag period of growth of methanogenic bacterium, Methanogenic formicicum, was observed to increase. At a total copper concentration of $300 \mathrm{mg} / \mathrm{L}$, complete inhibition occurred. A concentration in excess of $200 \mathrm{mg} / \mathrm{L}$ of the metal was required before severe inhibition of the methanogens was manifested. Chromium has a distinctive activity, as its salts, notably the sulphate, which is soluble. When chromium was introduced into the reactor system at $100 \mathrm{mg} / \mathrm{l}$ in trivalent state $(\mathrm{Cr}-\mathrm{III})$, a reduction in gas production of $80 \%$ was recorded. However, the metal as (Cr-VI) at an increased concentration of $420 \mathrm{mg} / \mathrm{l}$ was observed to cause only slight reduction in biogas production. The reasons for the variable effects of heavy metals and metal salts upon anaerobic reactor operation are not clear. One explanation suggested by [21] is that the concentration of precipitating agents such as sulfide and carbonate vary from system to system, thus altering the quantities of heavy metals that may be removed 
from the solution. Aggregation of the Methanogenic consortis in dense conglomerates retained in the reactor leads to an uncoupling of the hydraulic and microbial (solids) retention times. This key concept resulted in the successful implementation of anaerobic digestion for the treatment of a variety of wastes. The methanogenic aggregates are usually in the form of a biofilm (i.e., biomass attached to support media) or are suspended and retained in the reactor by special solid-liquid-gas separation structures. As the size of the aggregate increases, the surface area-volume ratio decreases and the in-flux of substrates or out-flux of products may become the limiting step in the overall substrate removal kinetics.

\subsubsection{Start-up and operation of anaerobic system}

The successful start-up and operation of an anaerobic system requires that a proper balance be maintained between the hydrolytic and fermentative organisms involved in the first step and the methanogenic organisms responsible for the second step. This balance is accomplished through proper seeding, as well as through control of organic acid production and $\mathrm{pH}$ during start-up, when microbial populations are establishing themselves. Ideally, an anaerobic reactor is seeded with digested sludge or biosolids from an active anaerobic treatment system. This kind of balanced, active seeding is necessary because of the slow doubling times of the critical microorganisms involved in the second step. If the seed contains only a small number of methanogens, the start-up may be long. During start-up, the operator must maintain a sufficiently small loading on the reactor so that the organic acids produced by the much faster growing fermentative bacteria do not exceed the buffering capacity of the system. If this occurs, the $\mathrm{pH}$ will drop, and the methanogenic population can be killed. The crucial steps during start-up are:1. Begin with as much good anaerobic seed as possible. 2.Fill the digester with this seed and water. 3.Bring the system to temperature. 4. Add buffering material in form of chemical such as sodium bicarbonate to protect against $\mathrm{pH}$ drop. 5.Add a small amount of organic waste sufficient to let the organic acid content from fermentation reach no more than about 2000 to $4000 \mathrm{mg} / \mathrm{L}$, while keeping pH between 6.8 and 7.6. These organic acids are the food source required for the methanogenic population to grow. The time when sufficient doublings have occurred will be evidenced through a drop in the organic acid concentration. Feeding with additional waste can then be initiated, slowly at first, until a balance is reached between step 1 and step 2 in the reactions in the system. At such balance, the organic acid concentration will generally remain below 100 to $200 \mathrm{mg} / \mathrm{L}$, depending upon the loading on the system. [16].

\section{Conclusion}

Recently, increasing focus is being placed on clean energy alternatives for satisfying growing energy demand. In order to remedy the depletion of fossil fuels and their environmental misdeeds hydrogen has been suggested as the energy carrier of the future. Hydrogen has become a promising energy source because it is clean and has high conversion efficiency. Evidently, industrial effluents have substantial amount of organic composition and industrial development in rapid phase accounts for release of considerable amount of the effluents. Production of hydrogen gas via biological means is pollutant free, needs low energy inputs and is thereby considered a potential alternative to conventional physical/chemical methods for hydrogen production. Hydrogen production can be achieved by algae and cyanobacteria through photolysis of water and by anaerobic or photosynthetic bacteria through fermentative conversion of organic substrates in the presence or absence of light. In general, fermentation with anaerobic bacteria (dark fermentation) has a higher hydrogen production rate, but hydrogen production with photosynthetic bacteria (light fermentation) possesses a higher theoretical conversion. Industrial effluent treatment process by the anaerobic fermentation has the capability of generating hydrogen in the hydrolysis step. Anaerobic wastewater treatment technology is not only useful for environmental protection but also to consult present day energy crisis. In this context, the potential utility of industrial effluents for the recovery of hydrogen by less energy intensive anaerobic process in addition to wastewater treatment will account for both resource recovery and environmental management. Presently, different studies were conducted related to the factors effecting on generation of bio hydrogen. All conclusions are based on processing of monitoring process results, with accent on temperature, $\mathrm{pH}$, bicarbonate alkalinity, VFA, inorganic salts, sulfide soluble salts, in operation, heavy metals and nutrient requirement influence on the bio Hydrogen production for the Start-up and Operation of Anaerobic System. The main conclusion underlines the fact that the factors play an important role for the production of a larger quantity of bio hydrogen.

\section{Acknowledgements}

The author thankful to Environment Canada and Department of chemistry, University of Toronto for providing financial assistance and laboratory facilities to carry out the current study. The author also gratefully acknowledge the 
co-faculty members of the Department of chemistry, University of Toronto, for their moral support to complete this manuscript.

\section{References}

[1] S. Ghosh, J. R. Conrad, and D. L. Klass, Anaerobic acidogenesis of wastewater sludge, Journal of Water Pollution. Control Fed 47,(1975) 3045.

[2] J.A. Eastman, and J.F. Ferguson, Solubilization of particulate organic carbon during the acid phase of anaerobicdigestion, Journal Water Pollution Control Federation 53(3) (1981) 352-366.

[3] Y.Y. Li, and T.Noike, Upgrading of anaerobic digestion of waste activated sludge by thermal pre-treatment, Water Science and Technology 26 (1992) 857-866.

[4] K.KSamir, Y.SRao, C.Z.Tian, P.LBuddhi, R.D.T.Yagi, C.M.Kao, Bioenergy and biofuel from biowastes andbiomass. Reston, American Society of Civil Engineers (2010) 44.

[5] T.Decker, K. Menrad, Regulation and innovation in biogas technology in selected European countries,International Journal of Public Policy 2(2007) 89.

[6] S. Kumar, S.Mukherjee, S. Devotta , Anaerobic digestion of vegetable market waste in India, World Review of Science Technology and Sustainable Development 7(2010) 217.

[7] G. Lyberatos Skiadas , Modelling of anaerobic digestion - a review, Global Nest The International Journal 1(1999) 63-76.

[8] B.Demirel, P. Scherer, Production of methane from sugar beet silage without manure addition by a single-stage anaerobic digestion process, Biomass Bioengineering 32(2008) 203-209.

[9] A.J Ward, P.J Hobbs , P.J Holliman, D.L Jones , Optimisation of the anaerobic digestion of agricultural resources, Bioresource Technol 99(2008) 7928-7940.

[10] D.Surroop, R. Mohee,Comparative assessment of anaerobic digestion of municipal solid waste at mesophilic and thermophilic temperatures,International Journal of Environment Technology Management, 14 (2011)238.

[11] S. Venkata Mohan, and P.N. Sharma, Anaerobic Treatment Process for Pharmaceutical Wastewater, PharmaBio World 2(2003) 101-108.

[12] R. Hema krishna, S.Venkata Mohan, and A.V.V.S.Swamy, Evaluation of kinetic parameters for bio hydrogen production by anaerobic suspended growth reactor using synthetic feed and up Scaling anaerobic suspended Growth reactor using complex feed, International Journal of Chemistry, 3 (2011) 124-139. Doi:10.5539/ijc.v3n2p124.

[13] R.E. Speece, and McCarty, P.L, Nutrient Requirements and Biological solids accumulation in anaerobicdigestion,In Advances in Water Research. London: Pergamon Press (1964) 305-322.

[14] R.E Speece, Anaerobic Biotechnology for Industrial Wastewaters, Nashville: Archae Press 1996,

[15] Metcalf \& Eddy Inc, Wastewater Engineering: Treatment and Reuse. 4th Ed. New York: McGraw-Hill 2003.

[16] B.E Rittmann, and P. L McCarty, Environmental Biotechnology: Principles and Applications. Intl. Ed. New York: McGraw-Hill 2001.

[17] G. F. Parkin, and R.E. Speece, Modeling toxicity in methane fermentation system, Journal of Environmental Engineering, 108 (1982) 515531.

[18] P.L McCarty,Anaerobic Waste Treatment Fundamentals, Part III, Toxic Materials and Their Control, PublicWorks 95(Novenber) (1964) 9194.

[19] W. F, Owen,D.C Stuckey, J.B Healy , L.Y Young, and P.L. McCarty , Bioassay for monitoring biochemical methane potential and anaerobic toxicity, Water Research 13(1979) 485-492.

[20] M.J. McInerney and M.P. Bryant. Fuel Gas Production from Biomass, CRC Press, Boca Raton 1(1981) 19-46.

[21] P.Hillmer, H.Gest .H2 metabolism in photosynthetic bacterium Rhodopseudomonas capsulata: H2 production by growing cultures, Journal of Bacteriology 129 (1977) 724-731. 